Article - 75 years - Special Edition

\title{
Robotic Process Automation Extended with Artificial Intelligence Techniques in Power Distribution Utilities
}

\section{André Pedretti ${ }^{1}$}

https://orcid.org/0000-0003-1357-4911

Mariana Santini ${ }^{1}$

https://orcid.org/0000-0002-7196-3897

Josnei Scolimoski ${ }^{1}$

https://orcid.org/0000-0002-1511-0822

Mauro Henrique Brito de Queiroz ${ }^{1}$

https://orcid.org/0000-0002-8489-1829

\section{Frank Toshioka ${ }^{1}$}

https://orcid.org/0000-0002-4944-8987

Eloy de Paula Rocha Junior ${ }^{1}$

https://orcid.org/0000-0003-1239-9330

Nelson de Pauli Júnior ${ }^{1}$

https://orcid.org/0000-0002-1161-5890

Marcio Takashi Yomura ${ }^{1}$

https://orcid.org/0000-0001-9441-608X

\section{Clayton Hilgemberg da Costa ${ }^{2}$}

https://orcid.org/0000-0002-7117-1785

Fabio Alessandro Guerra ${ }^{2}$

https://orcid.org/0000-0001-8429-2263

\author{
Bruna Machado Mulinari ${ }^{2}$ \\ https://orcid.org/0000-0001-5838-6178 \\ Flavio Lori Grando ${ }^{2}$ \\ https://orcid.org/0000-0002-2563-4953
}

\begin{abstract}
Joceleide Dalla Costa Mumbelli ${ }^{2}$ https://orcid.org/0000-0003-0511-5811
\end{abstract}

Cláudio Inácio Almeida Costa ${ }^{2}$

https://orcid.org/0000-0002-1982-4283

\section{Germano Lambert Torres ${ }^{2}$}

https://orcid.org/0000-0003-3789-4696

Milton Pires Ramos ${ }^{2^{*}}$

https://orcid.org/0000-0002-9244-2417

${ }^{1}$ Copel - Companhia Paranaense de Energia, Curitiba, Paraná, Brazil; ${ }^{2}$ Gnarus Institute, R\&D Department, Itajubá, Minas Gerais, Brazil.

Editor-in-Chief: Alexandre Rasi Aoki

Associate Editor: Alexandre Rasi Aoki

Received: 2021.04.06; Accepted: 2021.04.28.

*Correspondence: miltonpiresramos@gmail.com, Tel.: +55-41-98402 3423 (M.P.R.).

\section{HIGHLIGHTS}

- In Power Distribution Utilities the management of power meters is critical.

- Power meters management can be very optimized using software robots.

- The use of RPA technology is a key aspect for Digital Transformation.

- The association of RPA and Al is feasible and strategic for any company.

Abstract: Robotic Process Automation (RPA) is one of the several important techniques currently available for companies in search of performance improvement. The step forward in RPA is its association with Artificial Intelligence for more skilled robots. This scenario is not different in Power Distribution Utilities, in which 
multitude of complex processes must be executed over different data sources. Making such situation even more complex, these processes are frequently regulated and subject to audit by external bodies. However, an old question remains: what should be robotized and what should be done by humans? This paper aims at partially answering the question in the context of data analysis tasks used for making decisions in complex processes. The research development is conducted based on an Artificial Intelligence methodology incorporated into one software robot (RPA) which acquires data automatically, treats and analyzes these data, helping the human professional take decisions in the process. It is applied to a real case process that is important for validating the research. Four approaches are tested in the data analysis, but only two are really used. The robot analyzes a series of information from an energy consumption meter. The detection of possible behavior deviations in the meter data is made by comparison with its data series. The robot is capable of prioritizing the detected occurrences in the energy consumption data, indicating to the human operator the most critical situations that require attention. The association of Artificial Intelligence and RPA is viable and can really apport important benefits to the company and teams, valuing human work and bringing more efficiency to the processes.

Keywords: Artificial Intelligence; Robotic Processes Automation; Machine Learning; Data Analytics; Power Distribution Utilities.

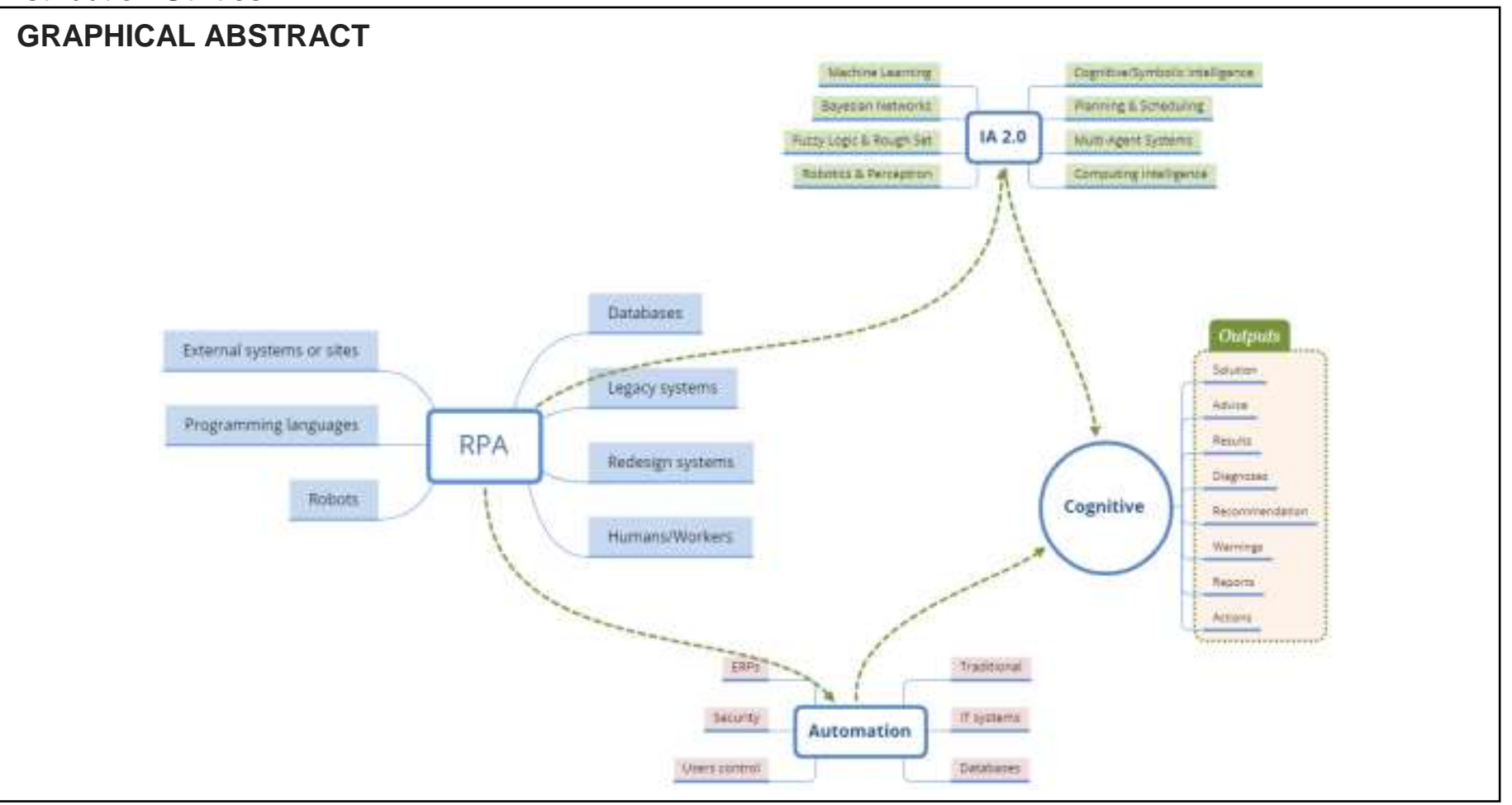

\section{INTRODUCTION}

The new generation of Artificial Intelligence (AI) is called Al 2.0 and has recently become an important focus of research in the academic and business fields due to its enormous potential for application and promising results. The Al 2.0 (data-driven) is in growing development, creating intelligent systems applied in the power or energy sectors more broadly. These energy applications are a crucial basis for the economic and social development, standing out for the observation of business processes and for the conception of the Business and Information System Engineering (BISE), which is the effective and efficient use of sociotechnical information systems applied in business engineering, with the objective of improving the social wellbeing of the individual, groups and the company [1].

That said, it is worth noting that power distribution companies have a large volume of information and processes to be executed, both manually and computationally, several legacy systems and various data sources. Making the environment even more complex is subject to audit and regulated by external bodies, such as ANEEL (Agência Nacional de Energia Elétrica - the National Electric Energy Agency), ONS (Operador Nacional do Sistema Elétrico - the National Power System Operation), CCEE (Câmara de Comercialização de Energia Elétrica - the Electric Power Commercialization Chamber), among others. Some examples of areas with such regulatory characteristics are: real estate management, assets management, 
commercial procedures (invoicing, billing, and collection), information technology, human resources, finances and treasury, supplies, accounting and engineering [2].

In this environment, many companies are devoting efforts to apply the Robotic Process Automation (RPA), technology which can be defined as the automation of processes imitating human actions, via software robots and without requiring human intervention. In this way, it allows the development and creation of computer systems in which it is possible to completely integrate actions and tasks that the humans perform in their digital environment. Therefore, a robot (or bot) is provided by an RPA platform that contains the computational description of the process, and then the robot will be able to imitate human tasks in order to robotize them. RPA stands out in the execution of tasks containing several limitless stages. It can handle structured and semi-structured data efficiently, offering best results in each execution. It can also perform tiresome, repetitive or simply form-filling tasks which will help the power distribution company liberate personnel for activities that add more value to both [3-5].

Together with an RPA platform, the concept of Robotic Cognitive Automation (RCA) can be included in processes with a complex environment and a great amount of data, It is the use of Artificial Intelligence (Al) techniques: machine learning (ML), data analytics, deep learning, among others, so as to incorporate the emulated human cognition into the solution of complex processes [4]. RPA is supported by the process, while RCA is supported by data and can initially apply machine learning techniques for data analysis and decisionmaking, reaching the application of Al techniques for deductive analysis [6-8].

Consequently, RPA, Al and Automation are presented as the main entities of an important technological arrangement, as shown in Figure 01. Each entity has specific functions of operation, aiming excellent results, combining intelligence, software robots and traditional automation. The main objective of this arrangement is to produce smart and useful solutions to the business, which can be in the form of actions, reports, recommendations, solutions, among others [5] [9].

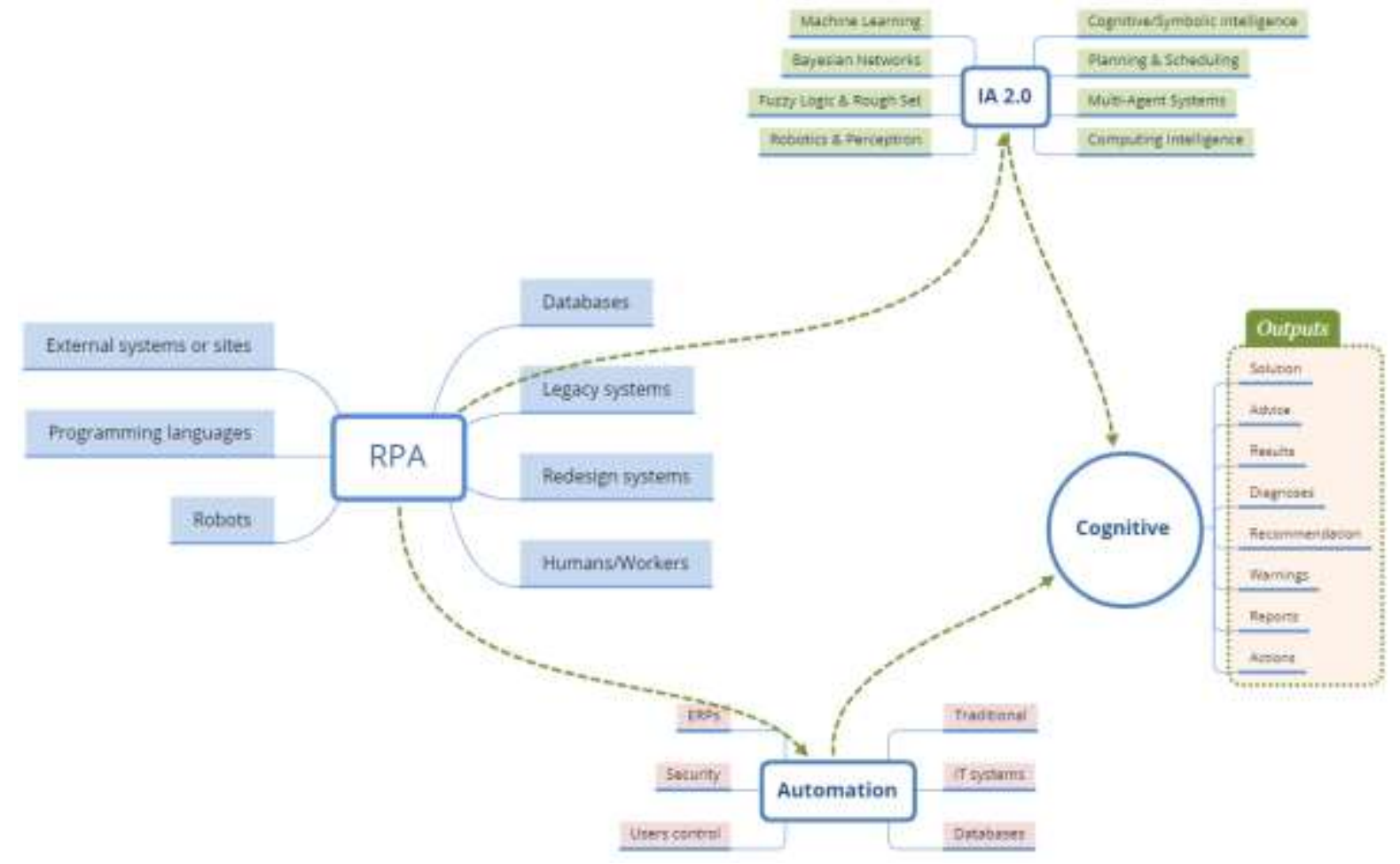

Figure 1. Technological arrangement using RPA, Al and traditional Automation.

The main motivation of this research is to answer the question: what should be automated and what should be done by humans? Then, another question arises: How could Al be used to optimize the value of RPA? To obtain answers to these questions, a case study is presented in a real application at the COPEL Distribuição (Power Distribution Utility), located in the state of Paraná - Brazil. In this case study, the RPA robot aims at searching information, accessing systems, treating, changing or replacing data that might be audit. Additionally, the methodology based on artificial intelligence aims at predicting and identifying the behavior of the energy meters involved in this process. 


\section{Case Study}

The case study is related to the CCEE Integration process. The Electric Power Commercialization Chamber (CCEE) is a Brazilian organization that operates the activities of buying and selling energy and promotes discussions on the evolution of the market, always guided by the pillars of isonomy, transparency and reliability. CCEE plays a critical role in accounting and financial settlement in the short-term energy market, as some great consumers can choose from which power agent they will buy electricity. Such free energy consumers can create their own strategy and negotiate the commercial terms on the contract. One of the main activities of CCEE is the accounting of purchase and sale of electricity, calculating the differences between the amounts contracted and the amounts actually generated or consumed by market agents (utilities and free consumers) on a monthly basis. To do so, CCEE monitors a nationwide network of power meters. Thus, the importance of this process for an energy distribution utility is undeniable. The company needs to keep track of the accounting performed by the CCEE each month - this accounting means the company's income.

In the case studied in this research, the application was restricted to meters that affect Copel's distribution structure, that is to say, 2,000 power consumption meters (in kWh). The CCEE system captures 12 consumption data per hour from each meter. This represents about 17.3 million energy consumption data to be analyzed per month, only in Copel's distribution coverage area - a huge task! In order to calculate the accounting for the utility, this amount of data is aggregated to 1 measure per hour per power meter, meaning 1.4 million data to be analyzed each month - still a task that demands a lot of attention and where computational support is crucial.

In this context, the task in the study aims at changing or replacing missing or incorrect information from energy meters in the CCEE system. Such inaccurate information can occur due to factors such as commissioning, deactivation, preventive maintenance, meter replacement, among others [10]. For this reason, the CCEE system establishes rules that allow to change this information. To meet these standards and perform the process of changing or complementing information in the system, the flowchart represented in Figure 02 was created to orient the robot action.

The execution flow starts with the robot receiving an e-mail with the energy meters data from HEMERA system (developed by the CAS Tecnologia Company). This system is responsible for the collection and storage of these data. The robot copies the data in a specific folder on the corporate computer network, which will be used for verification and comparison with the data from these same meters in the CCEE system.

Then, the robot verifies the number of files in the final reports folder. The existence of files in this folder depends on whether the person responsible for this process in the company approves the changes and/or substitutions proposed in the file by the robot before they are sent to the CCEE system. If there are files in the final reports folder, it means that the robot can send such information to the CCEE system, so that the information contained in those files will be replaced and consolidated by the CCEE system. Before sending the files with the modified information, they must be in the standard format used by the system, the XML (eXtensible Markup Language). After converting the files and sending the information, the robot forwards an e-mail with the files to be loaded into the CCEE system to the person in charge of the process, so that the altered information can be validated. Afterwards, the robot deletes the files in the folder to avoid resending them, in case the flow is started again.

With the information already changed and sent to the CCEE system, after the data from the meters have been completed, it is possible to carry out the analysis and forecast of the meters with abnormal behavior by comparing them with normal operating standards through the developed intelligent methodology (AI). The measurement points out of standard are reported to the measuring team for analysis. After forwarding the report, the robot registers its conclusion in the log file.

Yet, if there are no files in the final reports folder, the robot has to generate the spreadsheets in MSExcel format to be assessed by the person in charge of the process. Thus, the robot accesses the information found on the CCEE website for the current period, checks for missing or incomplete information and compares it with the information from the HEMERA system. Based on these verifications, the robot will make appropriate adjustment to the inconsistent findings. All this, together with the information on the modified measures, is e-mailed to the technician in charge of the process in an MS-Excel file, while the robot stores its completion in the record file. The person in charge analyzes the modified information and, if approved, the data sheet is saved in the final reports folder.

One word about the tools used to carry out this research: 
- The Copel Distribuição has already adopted an RPA platform, the Automation Anywhere, so all the work related to modeling, development, testing and running of robots was made on this platform.

- All other developments for the integration of robots with other systems, the analysis of data series carried out using the developed methodology (next section) and all other required functionalities were developed in Python programming language (Anaconda suite) and its Machine Learning libraries.

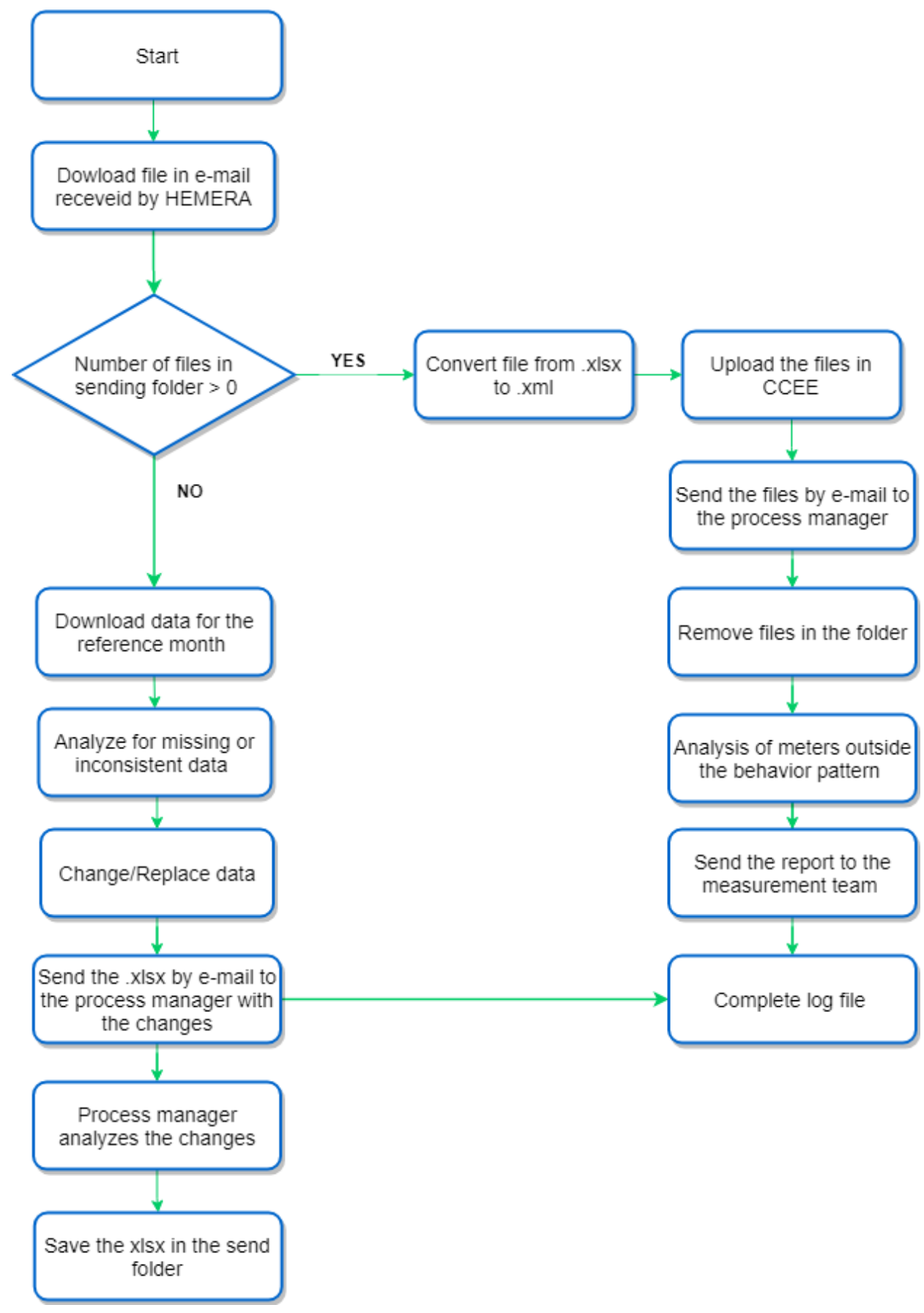

Figure 2. Flowchart of the robot acting in the CCEE process.

\section{METHODOLOGY BASED ON ARTIFICIAL INTELLIGENCE}

The first step of the methodology used for assessing the behavior of the meter data is to robotize the process of missing data (previous section), that is, to monitor the frequency of the missing measurements and use a calculation rule based on the regulations of the energy segment. Such procedure is repeated in each meter on a monthly basis. The large number of meters and measures each month, as well as the tight 
deadline for such changes, justify the implementation of robotization, via software robot (RPA), to perform this task. It is worth noting that this step is described in the flow presented above (Figure 02).

The second step of the methodology, on the other hand, consists of the analysis of the process meters behavior. As already mentioned, there is a large number of meters installed at a constant rate of new additions every month. This implies an excessive volume of data whose analysis in due time is not viable, unless an excessive number of people is hired exclusively for this job. This analysis helps to detect several problems and critical cases that require special attention from the team in charge, such as energy meters malfunction, inconsistent measurements, suspicion of fraud, rising rates of consumption without changes in the terms of the contract, among other possible adversities [11-15].

In other words, the objective of this step is, in a robotic and intelligent way, to reduce the number of meters that must be analyzed and verified by the responsible team, in order to enable the identification of problems in the short time available for such. This was done through historical analysis of the meter behavior, that is, in addition of using the data obtained in the previous step, the measurement data from previous months are also used to support the choice of meters that will be indicated for analysis by the responsible team.

In short, this second step of methodology can be divided into the following sub-steps: (i) Detection of interruptions; (ii) Detection of abrupt variation; (iii) Detection of a clear trend of variation; and (iv) Machine Learning techniques applied.

\section{i. Detection of interruptions}

The identification of interruptions consists of an algorithm that identifies points where zero consumption is measured in an unusual period for such occurrence, taking into account the meter data in the same period on previous days and mainly on the same day of the week in previous weeks and on the same day of the month in previous months. Figure 3 shows an example of a meter that had three unexpected interruptions between the end of March and the beginning of April 2020.

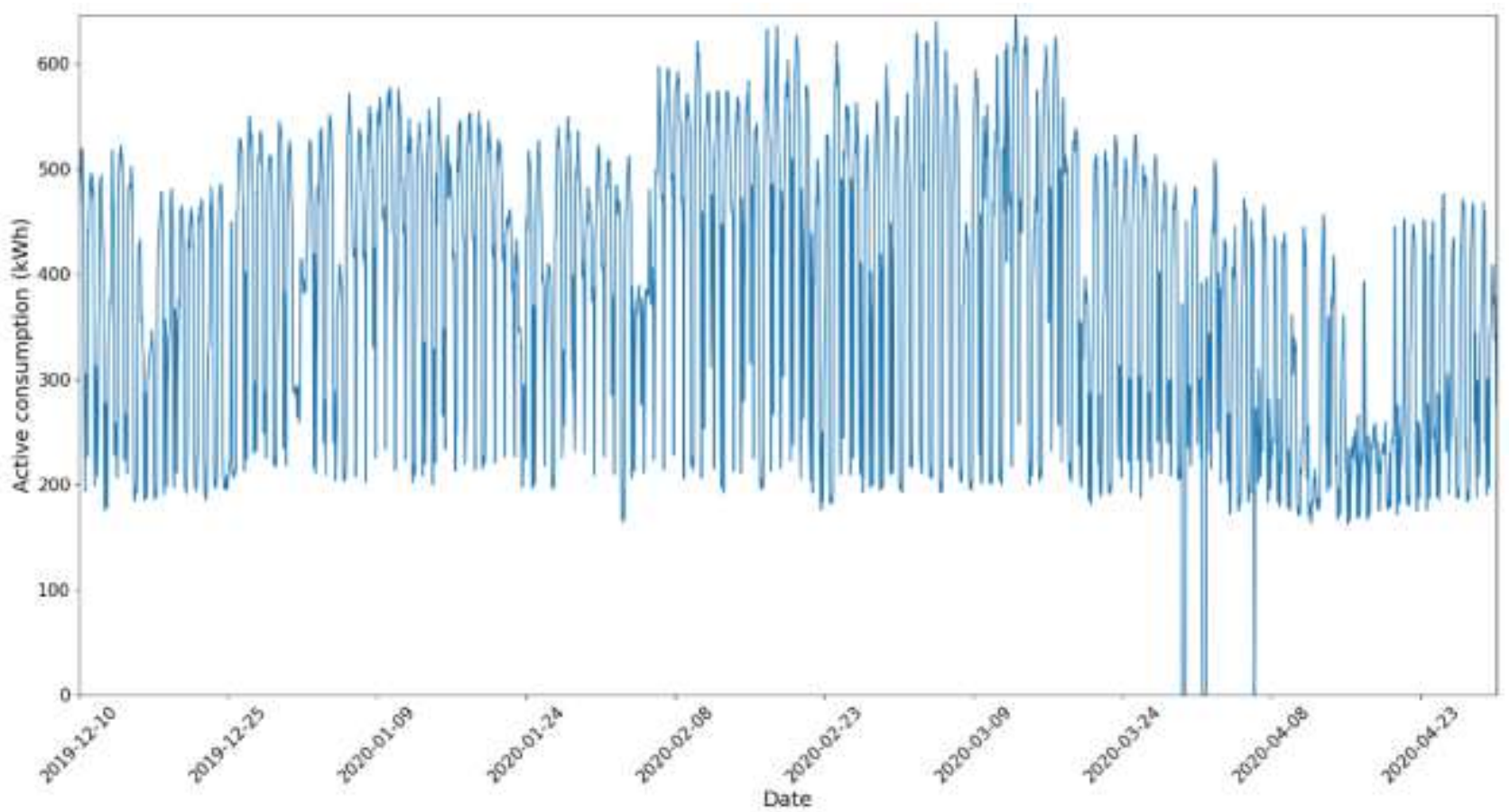

Figure 3. Example of a meter with interruptions.

\section{ii. Detection of abrupt variation}

The abrupt variation in a meter signal is detected by the verification of the average level of consumption for the month under analysis in relation to the previous month. It takes into account the history of the monthly standard deviation of the meters signal to see if they are within an acceptable tolerance limit. Additionally, if the information on variations between the same months in previous years is available, it can be used since a variation (though a high one) may be normal when considering the seasonal aspects of some meters. Figure 
4 illustrates a case of negative abrupt variation between the months of March and April 2020, still lasting at least until the beginning of May.

\section{iii. Detection of a clear trend of variation}

Similarly to the previous description, the detection of a significant trend of variation is the verification of the average level of power consumption, but in this case observing the variation of the last trimester (current month and the two previous months) in relation to the previous trimester. As in the case of abrupt variation, this variation is analyzed taking the history of the monthly standard deviation into account. When the information on consumption in a similar period of previous years is available, it can also be used. Figure 5 shows an example of a rising trend in consumption that started in December 2019 and lasted until February 2020.

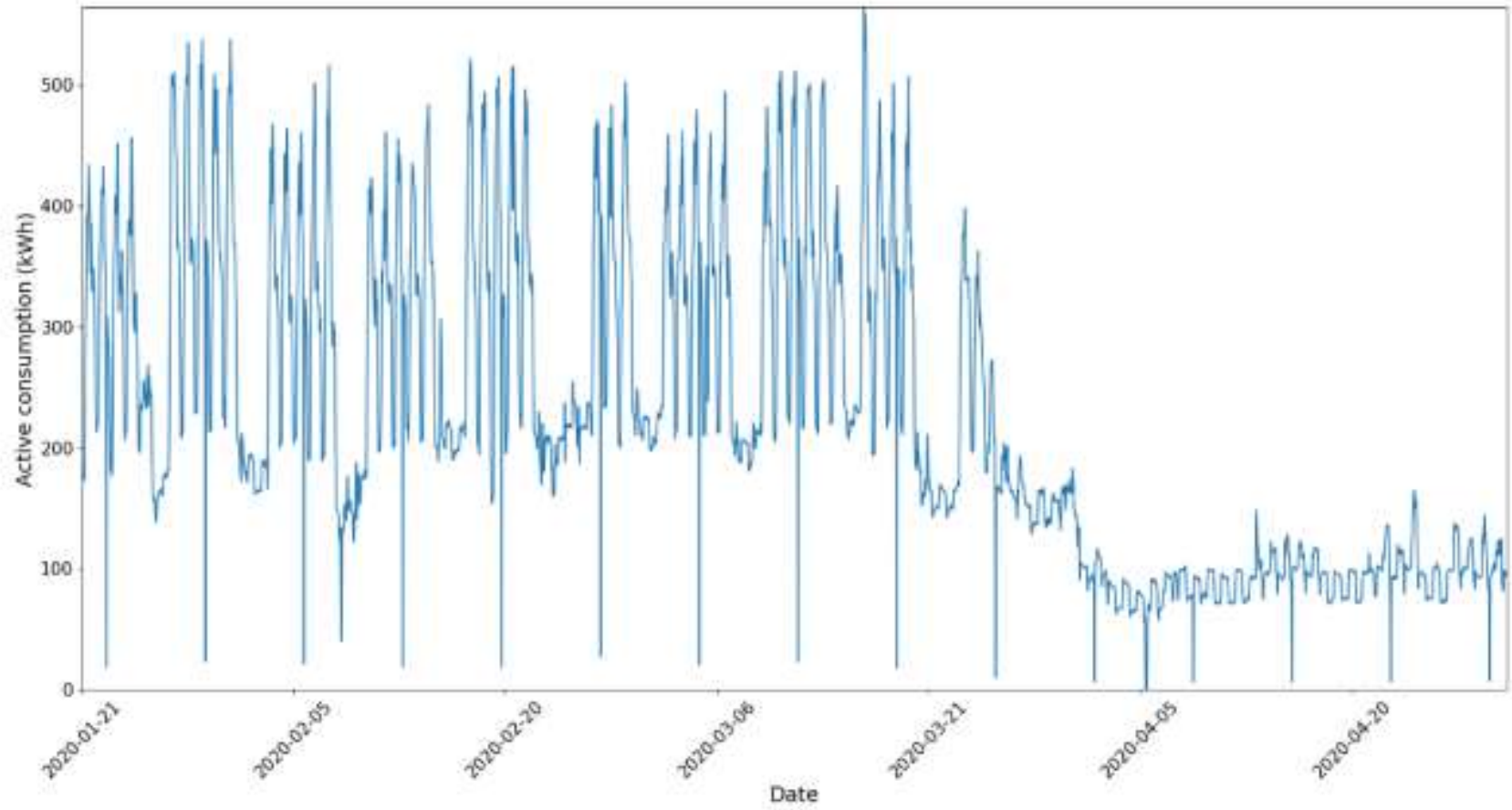

Figure 4. Example of a meter with an abrupt decrease in consumption.

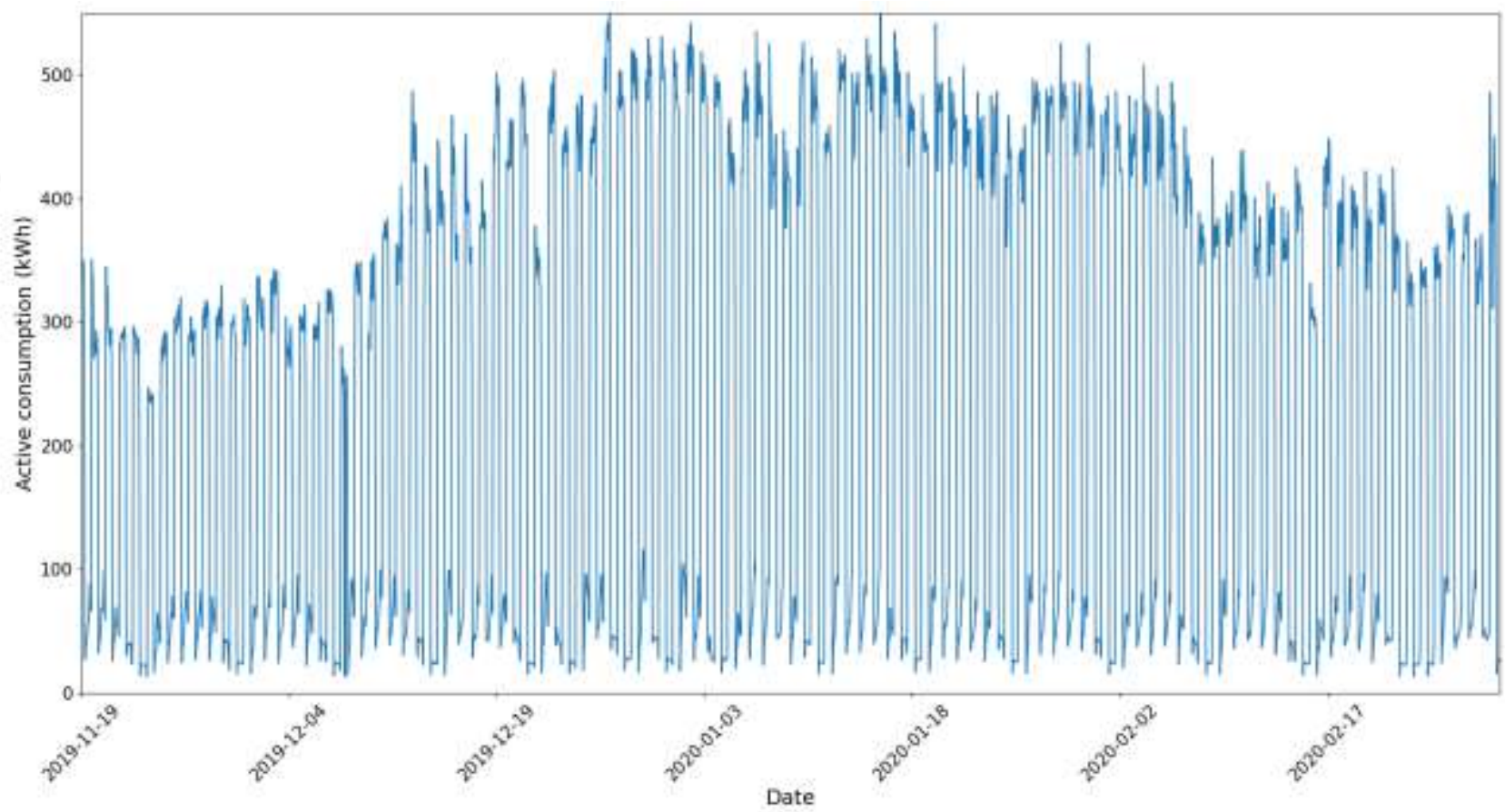

Figure 5. Case of consumption rising trend. 


\section{iv. Machine Learning techniques applied}

The following verification uses Machine Learning techniques to analyze the meters data in relation to their history, trying to identify deviations in the behavior beyond those approached in the previous actions or that consider the occurrence of multiple cases. Based on this, several regression and time series analysis models were selected and tested for good descriptors of meter behaviors. The techniques chosen and tested for this verification were: (a) Multiple Linear Regression [16]; (b) Random Forest [17]; (c) Autoregressive Integrated Moving Average (ARIMA) [18]; and (d) Long Short-Term Memory Recurrent Neural Network (LSTM-RNN) [19]. In addition, due to the fact that there are hundreds of meters, each one with its particularities of energy consumption level and behavior in relation to times and dates, a model per meter was developed instead of a single model trained with data from all the meters at the same time, so that the data of a given meter does not influence the others. In Figure 6, a case detected by using the Random Forest model shows a considerable peak in consumption at the end of November followed by a general drop in consumption in the following month.

The features selected for the construction of these models are: the day of the week, the day of the month, the month; the energy consumption on the same day and time like on the previous three weeks; a holiday indication (to show whether the day intended to forecast consumption is a holiday) and a holiday-eve indication in case there are long weekends.

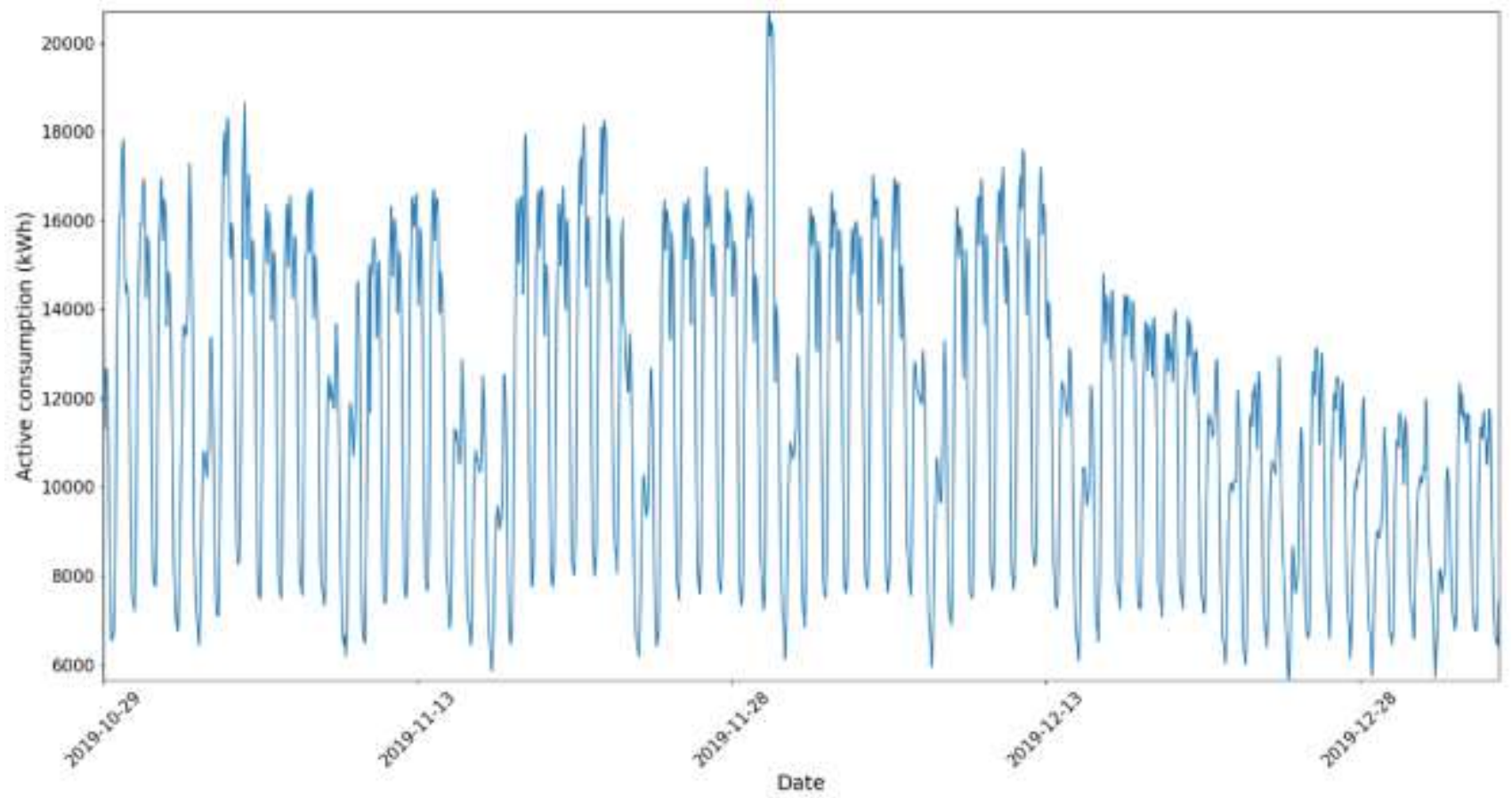

Figure 6. Case of behavior change.

\section{RESULTS AND DISCUSSION}

After the first performance tests, the ARIMA and LSTM models for Machine Learning (ML) were discarded due to their poor performance and inordinate length of training time. The training time length must be carefully considered because of the constant changes in the meters, as well as the entry of new ones in the system, so periodic retraining of the models is required. Thus, ML models with very long training time require unlimited availability of computational resources which still grow considerably with the aforementioned additions.

The two models resulting from the selection process mentioned-above (Multiple Linear Regression and Random Forest), have relevant features that deserve consideration. Concerning Multiple Linear Regression via the minimum-square method, the training takes place essentially by inversion, transposition and multiplication of matrices, which represents rapid training in up-to-date computers. However, as its name suggests, the linear regressor assumes that the relationship between the response variable and the set of characteristics is linear. Random Forests, on the other hand, are more appropriate to deal with nonlinearities, although they tend to take longer to be trained. Thus, both models were made available in the system to be used according to the availability of computational resources. 
The detection of possible behavior deviations in the power meters is made by comparing how well the $\mathrm{ML}$ model explains the data of the current month in relation to the previous eleven months, using the determination coefficient and the mean square error as metrics. In brief, for both models, twelve occurrences are trained, each one to forecast the consumption of a given month, between the current month of verification and the same month in the previous year. If the model is able to explain the data of the previous months well, and this does not occur in the current month, the attention of the team in charge is demanded.

Eventually, after all the analyses, the potential problems need prioritizing and are ranked in high, medium and low in importance. This prioritization guides the team responsible for the power meters on the appropriate course of action to follow. Such ranking is based on the potential severity of the problem and the existence, or not, of relevant information to the case in the previous period, as, for example, in the case of abrupt variation in the same months in previous years, as well as in the case of interruptions on the same day of the week in previous months. With this, we try to make the performance of the team in charge more flexible, enabling them to take immediate action in case of very serious problems and detect possible false alarms in due time.

In order to validate the obtained results, the precedent steps were taken from power meters with data from January to September 2020. In this period, data from 760 meters were made available. Table 1 shows the number of suspected problem cases, separated by priority, detected in each of these months.

Table 1. Suspected problem cases detected through September 2020.

\begin{tabular}{lccccccccc}
\hline & Jan. & Feb. & Mar. & Apr. & May. & Jun. & Jul. & Aug. & Sep. \\
\hline High & 3 & 3 & 6 & 30 & 6 & 23 & 6 & 6 & 5 \\
\hline Medium & 4 & 1 & 8 & 39 & 14 & 1 & 11 & 2 \\
\hline Low & 0 & 8 & 6 & 12 & 9 & 11 & 9 & 4 \\
\hline
\end{tabular}

Source: The authors

A significant larger number of cases is observed in the months of April and June (a little lower). The relatively larger number of suspected cases in June is justified by the real occurrence of a problem in a region of Paraná, causing the interruption of measurement of 21 power meters simultaneously. What happened in April is directly related to the COVID-19 pandemic. This is because in this month there was a mass closing in trade and industry in the whole country, in an attempt to stop the increase in coronavirus contamination. Therefore, the occurrences in April are closely related to the cases of a dramatic decrease in consumption and an unexpected interruption of measuring. The cases presented in Figure 02 and Figure 03 above are examples of the occurrences caused by the closures resulting from the COVID-19 pandemic.

It is also possible to observe that the Machine Learning models are able to identify both cases already handled by the algorithm (interruptions, variations and trends of variation), as well as new cases that have to be evaluated by the team responsible for the identification or treatment of a detected problem. Figure 7 shows a comparison between the real measured data and the data predicted by the Random Forest model for a given meter. Additionally, at the end of the month there is a great deviation in behavior in relation to what is expected by the model. Another interesting point is that, since it is a model that uses data from previous weeks, the tendency is that if the behavior change is correct (against a failure or problem in the power network), the model tends to be adapted. Thus, the suspected alarms will stop in a short time, which can be seen around April 29, when the model forecast is closer to the new behavior of the meter. 


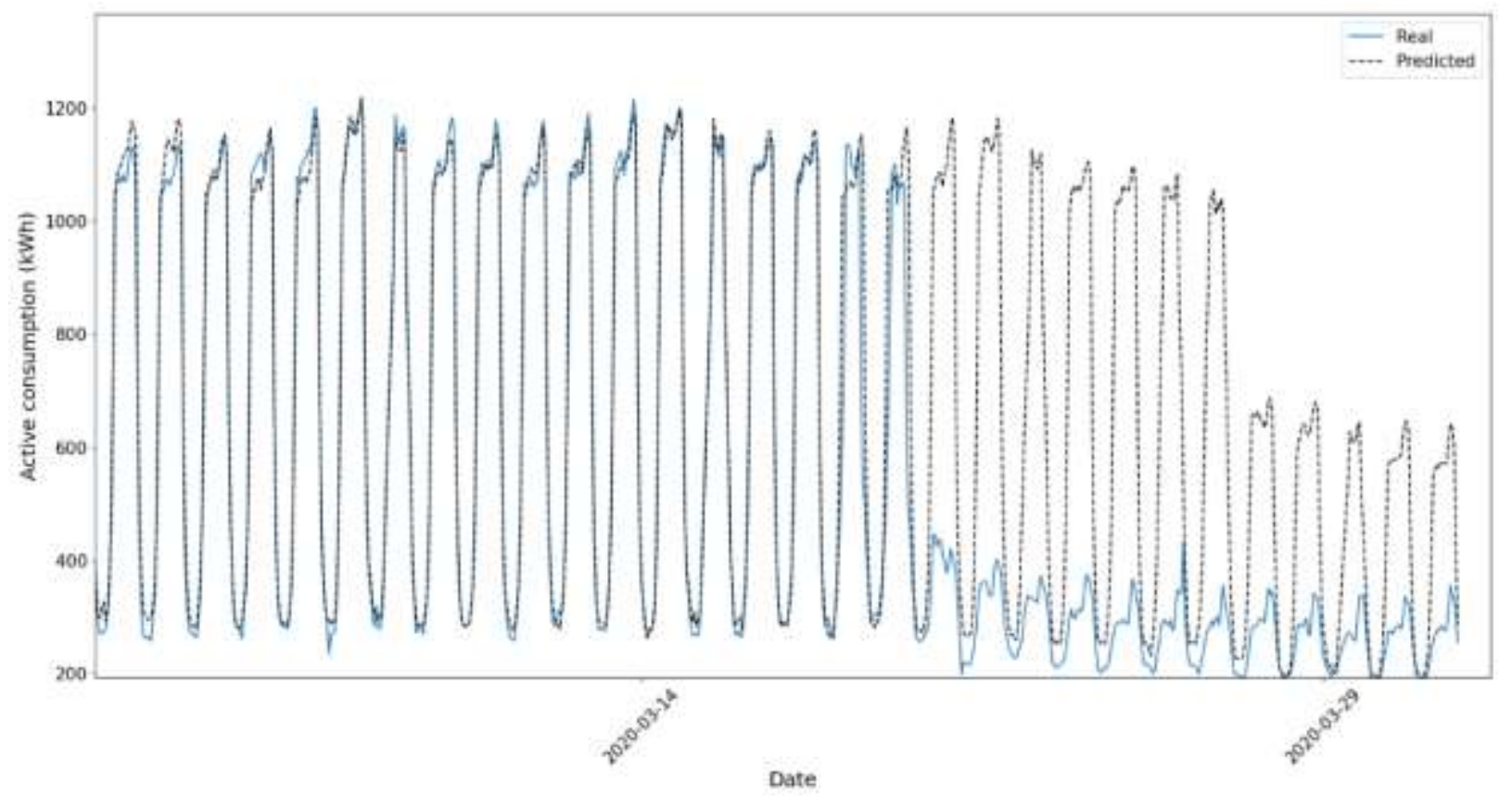

Figure 7. Comparison between the real measured data and model's forecast data.

\section{CONCLUSION}

With the improvement of the Robotic Process Automation Technology (RPA), the potential to optimize processes all over the business world is growing significantly. While software developers work to build customized solutions for in-house processes, the companies do not have to wait for such and can implement an RPA solution, which saves time and costs to the company. Due to the wide scope of its application, the process robotization is being widely used in different domains and sectors such as: energy, manufacturing, retail, analysis, aviation, oil and gas, and law. In the near future, data entry and organization work in information systems will be managed with robotic tools and techniques. All computer-aided processes that are ruled by a set of protocols will be managed with the help of this technology.

Concerning the expected Digital Transformation, there is a practically inevitable consequence after the use of RPA. It is the insertion of Artificial Intelligence (AI) and Machine Learning (ML) algorithms into software robots. Sometimes, the RPA robot will not know how to make a decision, so these algorithms should be implemented (RCA). Today's organizations strongly rely on Al and ML to provide the digital transformation which does not eliminate human development but helps humans as a tool that enhances and accelerates that development. The main objective of this research is to answer the questions already asked: What should be automated and what should be done by humans? How could Al be used to optimize the value of RPA? The main benefit of RPA is to increase and accelerate manual and repetitive work and thus allow professionals to work at a higher cognitive level. We can say that the goal of $\mathrm{Al}$ is to assist the cognitive analysis, which, together with RPA, is capable of generating: (a) solutions; (bi) recommendations; (c) diagnoses; (d) warnings; (e) actions, etc. (see Figure 01). The overall results of this research demonstrate the viability of this approach.

Additionally, a case study was carried out with all the characteristics for the insertion of RPA and Al as a way to validate the original research proposal. These characteristics are: (1) repetitive activities; (2) the access to several systems; (3) a substantial amount of data; and (4) decision making. The obtained results consolidate the need of using RPA, when it comes to the processing of more than 2,000, measurement points containing 720 data per measurement point to be analyzed monthly. Thus, totalizing more than 1.4 million data to be analyzed, therefore making the analysis only made by humans unfeasible, as illustrated in figures 03, 04, 05 and 06. Regarding Al, it was possible to aggregate intelligence with the aforementioned algorithms to identify possible behavioral failures in power meters data that represent failures and loss of revenue, information which would not be observed by humans, as shown in figure 07.

During the development of the research, some difficulties and challenges emerged. Most of them were related to the access and integration of large amounts of data from different systems, each one with a 
access method. These difficulties led to different solutions, such as some pre-treatment of data and the use of the CCEE API. Other challenges related to the version of the RPA platform used in the project arose. This version brought difficulties for the robot to act directly on the graphical interface of some systems, making these accesses very slow. In addition, this version has no native interface with the Python Programming Language, which is used for the development of intelligent algorithms in the project. To solve these issues, the project team developed temporary solutions for the integration of Python modules in the robot. A new version of the RPA platform will be installed which, hopefully, will solve these issues in a more consistent way.

Finally, the objective of the project has been successfully accomplished, given the improvement of performance in the process with the increase of data analysis capacity promoted by the robot with $\mathrm{Al}$ techniques. Besides, the application in the case study leads to new and interesting possibilities of analysis to be explored. Such possibilities had not been seen or explored, precisely because of the lack of analysis capacity for such a large amount of data:

- Evaluating whether changes in the behavior of a power meter data series are the result of a real contract alteration.

- Creation of specific analysis rules for a specific customer/meter.

- Clusters of meters with a similar power consumption profile. Identification of a customer's baseline consumption to filter situations such as weekends, holidays and collective vacation.

Acknowledgments: This work was financed by the program for research and technological development of Companhia Paranaense de Energia - COPEL, through the project PD 02866-0507 / 2019, regulated by Agência Nacional de Energia Elétrica - ANEEL. The authors would like to thank COPEL and ANEEL for the opportunity and support.

Conflicts of Interest: The authors declare no conflict of interest.

\section{REFERENCES}

1. Lefeng Cheng and Tao Yu. A new generation of Al: A review and perspective on machine learning technologies applied to smart energy and electric power systems. Wiley Energ Res; 2019, 1-46 p. DOI: 10.1002/er.4333

2. Pedretti A, Guerra FA. RPA utilizando Machine Learning e Inteligência Cognitiva. Projeto de PeD ANEEL 28660507/2019. Copel Distribuição e Instituto Gnarus. Relatório Técnico 04; June 2020.

3. Özlen Erkal Sönmez \& Dilek Yılmaz Börekçi. A Conceptual Study on RPAs as of Intelligent Automation. Springer Nature Switzerland. 2020: 65-72. https://doi.org/10.1007/978-3-030-23756-1_10

4. Siderska J. Robotic Process Automation: a driver of digital transformation? Eng Manag Prod Serv. 2020; 12 (2): 21-31. doi: 10.2478/emj-2020-0009

5. Syed R, Suriadia S, Adamsa M, et al. Robotic Process Automation: Contemporary themes and challenges. Elsevier, Comput Ind. 2020;115:1-15. https://doi.org/10.1016/j.compind.2019.103162

6. Masood A. \& Hashmi A. Democratization of Al Using Cognitive Services. In: Cognitive Computing Recipes. Apress, Berkeley, CA. 2019. https://doi.org/10.1007/978-1-4842-4106-6_1

7. Souza GR, Bello IP, Corrêa FV, Oliveira LFC. Artificial Neural Networks for Filling Missing Streamflow Data in Rio do Carmo Basin, Minas Gerais, Brazil. Braz Arch Biol Techn (BABT). 2020; 63: 1-8. https://doi.org/10.1590/16784324-2020180522

8. Pepplow LA, Betini RC, Pereira TCG. Forecasting the Electricity Consumption in a Higher Education Institution. $\begin{array}{llllll}\text { Braz } & \text { Arch } & \text { Biol } & \text { Techn } & \text { (BABT). } & \text { 2019; }\end{array}$ https://doi.org/10.1590/1678-4324-smart-2019190004

9. Geetha T, Malini A, Indhumathi M. Robotic Process Automation. Int J Comput Techniques. 2020; 7 (5): 1-12. http://www.ijctjournal.org/volume7/issue5/ijct-v7i5p3.pdf

10. Pedretti A, Guerra FA. RPA utilizando Machine Learning e Inteligência Cognitiva. Projeto de PeD ANEEL 28660507/2019. Copel Distribuição e Instituto Gnarus. Relatório Técnico 02; December 2019.

11. Jung-Pin Lai, Yu-Ming Chang,et. al. A Survey of Machine Learning Models in Renewable Energy Predictions. Appl. Sci. 2020: 1-20. doi:10.3390/app10175975

12. Upadhaya D, Thakur R, Sing NK. A systematic review on the methods of short term load forecasting. In: Proceedings of the 2nd International Conference on Power Energy, Environment and Intelligent Control (PEEIC); 2019 Oct 18-19: U.P. India. p. 06-11.

13. Martína EG, Rodrigues CF, Riley G, Grahn H. Estimation of energy consumption in machine learning. Elsevier, J Parallel Distr Com. December 2019; Volume 134: 75-88. https://doi.org/10.1016/j.jpdc.2019.07.007 
14. Pedretti A, Guerra FA. RPA utilizando Machine Learning e Inteligência Cognitiva. Projeto de PeD ANEEL 28660507/2019. Copel Distribuição e Instituto Gnarus. Relatório Técnico 05; November 2020.

15. Mosavi A, Salimi M, Ardabili SF, et al. State of the Art of Machine Learning Models in Energy Systems, a Systematic Review. MDPI, Energies. 2019; 12 (1301): 1-42. doi:10.3390/en12071301 www.mdpi.com/journal/energies

16. Draper NR, Smith H. Applied Regression Analysis. 3rd ed. John Wiley \& Sons, Inc.; 1998.

17. Breiman L. Random Forests. Mach Learn. 2001; 45: 5-32.

18. Box GEP, Jenkins GM, Reinsel GC. Time Series Analysis: Forecasting and Control. 4th ed. John Wiley \& Sons Inc.; 2008.

19. Muzaffar S, Afshari A. Short-Term Load Forecasts Using LSTM Networks. Energy Procedia.2019,158,2922-7.

(c) 2021 by the authors. Submitted for possible open access publication under the terms and conditions of the Creative Commons Attribution (CC BY NC) license (https://creativecommons.org/licenses/by-nc/4.0/). 